Kriz Dergisi 3 (1-2): 175-178

\title{
PSIKIYATRIK OLGULARDA TOPLUMSAL YARGI
}

\author{
Murst BiLGiLj*
}

Dünya üzerinde yaşayan insan topluluklart içerisinde çoğunluktan farklı düşünce, konuşma ve davranışlara sahip olanlar hep dikkat çekmiştir. Normal, çoğunlukta bulunanı ifade ettiği gibi, normal davranış ta çoğunluğun davranış şekli olarak kabul edilmiştir. Ortalamadan (çoð̆unluktan) uzaklaşma ise anormal ile ifade edilirken, burada ortalama hiç bir insanın ruh sağlığı bakımından kusursuz olamayacağı bilgisine dayanmaktadır.

Ruh sağığında belirgin bozuklukları olan insanJar, toplum içerisinde çoğuntuktan farklı olduklarını, konuşma ve hareketleri ile ortaya koyarken, bu farkılık toplumda onlarla ilgili bazı yargıtarın oluşmasına neden olmuştur. Tarihin her döneminde, konuşmalarına, düşüncelerine ve hareketlerine bir anlam verilemeyen bu insanların, çevreleri için tehlikeli ve zararlı olacakları ana olumsuz düşüncesi ile hareket edilmiştir. "Onlar saldırgandır, suçludur. bir yere kapatımaları gereklidir..." şeklinde çŏgunluk tarafından ifade odilen bu sozzler, ruh sağığı bozuk olanlara karşı toplumda mevcut olan olum. suz yargıyı gőstermektedir. Yargı nedir?

Aristoteles yargı'yı "doğruluk ya da yanlışlık bildiren önerme" olarak tanımlarken, yargı Toplumbilim Terimieri Sőzlüğünde "doğru ya da yanlı̧̧ olabilen bir onne sürüm" olarak tanımlanınıştır. Toplumda bulunan bu olumsuz yargının, doğru ya da yanış olup olmadığını araştırmak kadar, oluşumuna neden olan etkenler de bizi ilgilendirmektedir.

*Dr., I.Ü. Istanbul Tip Fakóltesi. llkçağlardan 18. yüzyılın sonlarına kadar, bu insankar davranış bozukluğu gösteren kişiler olarak degerlendiriliyordu. Sahip olunan bozukluk Cüzzam (Lepra) gibi fiziksel deģişikliklere yol açarak kendini gőstermediğinden, hastalık olarak değerlendirilemiyordu. Bir olgunun nedenini bilmiyorum, bilmek isterim diyebilmek bilimsel düşüncenin onemli bir adımıdır. Oysa ki güçsüz ve güvensiz olan insan, bilinmezleri araştırmak yerine dogaüstü, bir başka deyimle kendinden üstün ve kendinin stesinde güçlere inanarak sorunları çözmeye çalışıyordu. Ancak 18. ve 19. yüzyılda gelişmeye başlayan bilimsel yơntemlerin ruhbilim'e yansıma. Sı, insanı tanımaya yardımcı olan ruhbilim oğretilerinin doğmasına yol açmışır. Dolayısıyla uzun ve acılarla dolu tarihsel süreçte, bu insanların hasta olarak kabul edilmeleri, bakım ve tedavilerinin ya. pılması çok yenidir.

Ancak değişmeden günümüze kadar gelen bir nokta, ruh hastalığı, böbrek veya kalp hastalığı buıunan kişiler aynı suçu işleseler dahi, ruh hastalığı olan kişinin günlerce gazete ve televizyonlarda ko. nuşuluyor ve toplumun ilgisini çekiyor olmasıdır. (Bunun en yakın ve en çarpıcı ơrneği insanları kafalarına çivi çakarak öldüren bir akıl hastası ile ilgili haberierin, en yüksek tiraja sahip gazetelerin ilk sayfalarnnda, en çok izlenen televizyonların haber programlarında yer alıyor ve insanların da olayı dehşetle izliyor olmalarıdır). Gerek tarihsel gelişirr. gerekse günümüzde halen, ruhsal bozukluğa sahip kişilerin hayatlarının "zarar verici, suç işieyici" kesitlerinin medya tarafından sevgi, acıma gibi duygular yaratacak şekilde değil de, dehşet, nefret uyandıra- 
cak şekılde topluma sunulınası olumsuz yargının oluşmasında çok onemlı rol oynamaktadır Insaniı. ğın çeşıtı alantarda aldığı, hayal sınırlarını bıle aşan ılerlemelere rağmen, en llerı ulkelerın en kulturlu olan insantarında bile henuz bu negatıf tavir ve dırencın kırılmadığını gösteren belırtıer çoktur Ozellıkle Amerika'da Dohrenwend, Elınson, Freeman, Gurın, Nunnallys Star (Jaekel, Weiser ve Relmann'dan) ve daha bırçoklarının halk arasında yaptıkları incelemeler bunu gostermektedır Insanoğlu'nun sahıp olduğu hıçbır hastalıkta benzer yargı bulunmazken, sadece ruhsal patolojisı bulunan kışilere yönelık olan bu olumsuz yarginin doğru olup olmadığının araşıırıması gerekmektedir

Bu gereklılıkten yola çıkılarak yapılan araştırma$\mathrm{da}$, çeşıtth suçlar ışlemış 2212 olgu incelemeye alınmış, normal olarak değerlendırıenter ile ruhsal patolojı gòsterenler karşılaştırımıştır Ruhsal patolojı gosterenler olarak tanımlanan grup "ceza ehltyetını" ortadan kaldıracak (TCK'nun 46 maddesı) veya azaltacak (TCK'nun 47 maddesı) mahiyet ve derecede psıkopatolojık araz gઠsteren kışılerden oluşmaktadır Karşılaştırmalar kı kare ıstatıksel yöntemıne gơre yapılmıştır Suç çeşıtlerı olarak adam oldurme, adam ơldurmeye tam teşebbus, yaralama, cınsel suçlar, gasp, hırsızlık, sahtekarlık, yangın çıkarma ve orman kanununa muhalefet suçları incelenmıştır Suçlar kendı ıçerısınde ozelIıklerı bakımından uç gruba ayrılmıştır

I grup bıreye yonelık şıddet ogesının on planda olduğu "adam oldurme, adam oldurmeye tam teşebbus, yaralama ve cınsel şuçlardan" oluşmaktadir

\section{Tablo I}

\begin{tabular}{|lcc|}
\hline & HASTA & NORMAL \\
MUESSIR FIIL & 104 & 112 \\
ADAM OLDURME & 197 & 547 \\
ADAM OLDURMEYE TEŞEBBUS & 42 & 73 \\
AHLAKA KARŞI IŞLENEN SUÇLAR & 56 & 99 \\
\hline
\end{tabular}

Tablo l'in değerlendırımesınde $\left(X^{2}=3822\right.$, $P<0$ 0001) ruhsal patoloj gosterenler ile normal kişler arasında belırtılen suçları ışłeme açısından ılerı derecede anlamlı bır farklıık bulunmuştur

Il grup "gasp, hırsızlık, sahtekarlık" suçlarından oluşmaktadir

\section{Tablo II}

\begin{tabular}{|lcc|}
\hline & HASTA & NORMAL \\
GASP & 11 & 96 \\
HIRSIZLIK & 82 & 292 \\
SAHTEKARLIK & 9 & 40 \\
\hline
\end{tabular}

Tablo Il'nın değerlendırılmesınde $\left(X^{2}=729\right.$, $p=0$ 0026) ruhsal patolojı gosterenier ile normal kışıler arasında belırtıen suçları ışleme açısından anlamiı bır farklilık bulunduğu sonucu elde edılmıştır

III grup yangın çıkarma ve orman kanununa muhalefet" suçlarından oluşmaktadır

Tablo III

\begin{tabular}{|lcc|}
\hline & HASTA & NORMAL \\
YANGIN ÇIKARTMA & 18 & 25 \\
ORMAN KANUNUNA MUHALEFET & 22 & 19 \\
\hline
\end{tabular}

Tablo Ill'un değerlendırımesınde $\left(X^{2}=127\right.$, $P=0$ 27) belırtılen suçları ışleme açısından her ıkı grup arasında anlamlı bır farklıtık bulunamamıştır Burada dıkkatı çeken nokta oransal olarak ruhsal patolof gosterenlerın normal kışılere oranla daha yuksek sayıda bulunmasıdır Bu yukseklık çoğunlukla suçun akıl hastası olarak nıtelendirılen kışılere ceza verılmeyeceğı duşuncesıyle yuklenmesı ya da failın saptanamadiğı durumiarda potansıyel zaniı olarak duşunulmelerınden kaynakianabıımektedır

Toplum hayatını bozan, çoğu zaman duzeltımesı olanaksız maddı ve manevı yaralar açan adam oldurme, adam oldurmeye tam teşebbus, yaralama, cınsel suçlar, sahtekarlık, gasp ve hırsızlık suçlarını, normał olarak değerlendırıen ınsanlar ruhsal patoloj: gosterenlere oranla daha fazla ışlemektedırler Çalışmayı oluşturan olguların Adlı Tıp Kurumundan alınmış olması sonucu daha çarpıcı kılmaktadır Çunku her suç ışleyen kışı Adiı Tıp Ku rumuna muayeneye gonderılmez Muayeneye gonderılebılmesı ıçın psıkıyatrık geçmışının veya akıl hastalığı şuphesının bulunması gerekır

Bu unsanlar "suç ışleyen, saldırgan, tehlıkelı" ofmadıkları gıbı suç ışlememe konusunda da bızler kadar duyarlıık gostermektedırler KıskançlıkBoşanma Eşı Oldurme Uçgenı ısımlı çalışmamızın sonucu bu duyarlıı̆̆ en ıyı şekilde ortaya koymak. 
tadır. Çalışmada kıskançlık nedeniyle eşini oldüren veya yaralayan 242 olgu incelenmiştir. Aklen sağlam (ceza ehliyeti tam) olarak değerlendirilen 138 sanığın \%41.3'ü, yani 57 sanık, sư̧ eylemine girişmeden once mahkemeye başvurma, eşlerini anne, baba veya kardeşlere yollama veya evi ter. ketme gibi girişimlere başvurmuştur. Bu yollara başvurmalarına rağmen, yakınlarının araya girmesi veya boşanmalarına yeterli sayılacak delillerin eksikliği nedeniyle davanın reddedilmesi gibi sebepierle, birlikteliklerin suç tarihine kadar zorla sürdürüldüğü belirlenmiştir. Aynı şekilde ruhsal patoloji nedeniyle ceza ehliyetieri etkilenmiş olan 104 olgudan 43 tanesi (\%41.3) eşini oldürmeden veya yaralamadan önce mahkemeye başvurma gibi benzeri girişimlerde bulunmuşlardır. ister aklen sağlam, isterse hasta olsun sanıkların \%41.3'ünün suçu oluşturacak eylemlerinden once on bir girişim olarak kendilerini, eşlerini ve de toplumu böylesine saldirgan ve istenmeyen bir eylemden korumak amaçyla eşlerinden ayrılmayı denemişlerdir.

Kültürel etkenler, toplumun ve ailenin kendi ruh hastasına karşı yargıları tedavi sonucu ve sosyal uyum için büyük önem taşırlar. Örneğin: Hindistan ve Afrika'nın bazi bolgelerinde akil hastalarına karşı daha hoşgörülü anlayışıı davranııdığını gơzlemler göstermektedir. Bðyle bir toplumda akıl hastasırın topluma uyumu, dolayısıyla da hastalığın gidişi ve prognostiğinin daha iyi olacağı yazarların çoğu tarafından paylaşılan bir düşüncedir. Dił̌er taraftan gerek günlük gözlemler gerekse çeşitli sosyal, psikolojik incelemeler batı toplumunun akıl hastasına karşı negatif, itici, reddedici yargılara sahip olduğunu göstermektedir. Bð̋le kendi hastası ile arasında görünmez ve çok etkili duvarların bulunduğu bit toplumda hastalık gidişi ve progno. zunun birinci tip toplumdakinden farklı olacağı aşikardır.

Schulte çalışmasında sosyal psikiyatrinin hastaya iyi bir prognoz hazırlamak için aile, çevre ve

\section{KAYNAKLAR}

1) Baeyer, W.R.; Die Verantwortung der Gesellschaft für ihr Psychish Kranken. Soc. Psych. 2, 1, 1966.

2) Hafner, $H$, Zerssen, V:: Soziale Rehabilitation ein integrierender Bestandteil Psychiatrische Therapie. Der Nervenarzt, 6, 1964. işyeri uzerinde gőstermesi gereken büyük çabaya dikkat çeker. Cooper' in hasta olmadan once bir ailesi ve grubu bulunupta, hastalıktan sonra da tekrar o aile ve gruba dð̋nenlerin daha iyi bir şansa sahip olduğunu bildirmesine karşılık yine lngiltere'den Brown hastalıktan şifa bulmuşların, daha çok affektif yüklenmelerle karşılaşacağı aile yuvası yerine, nötr olan bir çevreye dönmelerini savuinur.

Hastaların çeşitli derecelerde gőrev ve sorumluluk yokklenmelerini sağlama, onları topluma kazandırma yolları ve gerek kişi, toplum ruh sağlığı, gerekse ekonomik yönden bundan sağlanacak kazanç çok aşikardır.

Ulusal üretim ve ekonomik potens açısından da ruh hastalıkları bir çok diḡer hastalıklar yanında ayrı bir onem kazanırlar. Erken ve yeter derecede sistemli tedaviye alınmadıkları zaman çoğunun iyileşmesi güçleşir, bơylece kendileri üretici olmaktan çıktıkları gibi, hayatları boyunca da ailelerine ve topluma yük olurlar. ABD'de ve Kanada'da ruh hastalarının tedavi ve bakımına sarf edilen açık paraya oranla, hastaların erken yaşlarda üretkenliklerini kaybetmeleri sonucu meydana gelen dolaylı kaybın daha fazla olduğu bildirilmiştir.

Sonuç olarak toplumdaki bu ołumsuz yargının yanlış olduğunun ortaya çıkması ve "bu insanlar saldırgan değildir, onlardan korkmaya, onları toplumdan uzaklaştırmaya gerek yoktur, kalp veya şeker hastaları gibi bu insanların da ilaçlarını kullandıkları ve kontrollerine gittikleri takdirde sosyal hayatın gereklerini yerine getirememeleri için hiç bir neden yoktur" şøklinde düşüncelere yerini bırakması hepimizi ilgilendirmektedir. Şoyleki hastanede tedavisi bittikten sonra toplum hayatına geri dőnen bu insanlar dışlanmayacaklar, kendilerine korkuyla, potansiyel tehlike olarak bakmayan, anlamaya, yardımcı olmaya çalışan insantarın arasında sosyal uyum sağlayarak ve üretkenliklerini sürdürerek, çevrelerine ve topluma yük olmadan yaşayacaklardir.

3) Jaekel, M. und Wieser, St: Studien zur "Unsichtbaren Schranke" bei psychisch Kranken. Soc. Psychiatr, 3, 100, 1967.

4) Kulenkampff, $C_{\text {.: }}$ Psychiatrie in der Sowjetunion. Soc. Psychiatr, 2, 124, 1967.

5) Reimann, H.: Dei Gesellschaft und der Geisteskranke. Soc. Psychiatr. 3, 87, 1969. 


$\begin{array}{llll}K & R & \text { I } & \text { Z }\end{array}$

6) Zitrin A, Mardesty A.S., Burdock E.I., Drassman A.K., Crime and Violence Among Mental Patients, Am. J. Psyciat, 1976.

7) Robertson G., Arrest Patterns Among Mentaly Disordered Olfenders, Bri. J. Psychiat. 1988.

8) Grunberg F., Klinger B.1., Grumet B.R., Homocide and the deinstituonalisation of the mentally ill, Am. J. Psychiat, 1977.
9) Saussure Y., Comment peut on criminel, L'age d'homme, 1979

10) Nestor P.G., Neuropsychogical and other forms of extreme violence of in a forensic psychiatric population, J. Nen. Ment. Dis., 1992.

11) Noreik K, Gravem A., Homicide and Mental Disease, Tidsskr. Nor. Laegoloven 1993. 